\title{
The Influence of Nursing Job Satisfaction on Nursing Innovation: An Examination of the Conditions of Nurses in Public Preschools in Taiwan
}

\author{
Yu-Hua Yan ${ }^{1}$, Chih-Ming Kung ${ }^{2}$, Yu-Li Lan ${ }^{3}$, Liang-Hsi Kung ${ }^{4}$, Chao-Jung Lee ${ }^{5 *}$ \\ ${ }^{1,5}$ Tainan Municipal Hospital (Managed by Show Chwan Medical Care Corporation) \\ ${ }^{2}$ Shih Chien University Kaohsiung Campus \\ ${ }^{3}$ Tzu Chi University of Science and Technology \\ ${ }^{4}$ Chung Hwa University of Medical Technology
}

*Corresponding Author: Chao-Jung Lee, Nursing Department, Tainan Municipal Hospital (Managed by Show Chwan Medical Care Corporation). Taiwan Email: 2d0003@mail.tmh.org.tw

\begin{abstract}
This study aims to examine the job satisfaction of nursing work with the staff nurses in preschools in Taiwan as the object of study to explore the influence of job satisfaction of nursing work on the innovation of nursing. In Taiwan, there are about 650 preschools. Anonymous return mail was posted to conduct a full-scale survey, with the return of 219 valid questionnaires (33.69\%). The 219 valid questionnaires underwent Pearson correlation analysis and multiple regressions analysis. The three factors of the influence of innovative behavior, innovative capacity, and innovative diffusion, the statistic of wage and welfare show to be significant $(<0.05)$, influencing the factors of knowledge creation, professional autonomy, and wage and welfare ( $p<0.01)$. It is suggested that Taiwan government regulate and establish the domain of services of nursing in schools to promote the professional and innovative capacities of nursing professionals (or staff nurses).
\end{abstract}

Keywords: Job Satisfaction, Nursing Innovation, Knowledge Creation, Professional Autonomy

\section{INTRODUCTION}

According to the "Early Childhood Education and Care Act" of Taiwan," Preschools and their branches that have a total number of less than 60 children may employ contracted or part-time nurses. For a total of 61 to 200 children, contracted, part-time or full-time nurses shall be employed; for a total of more than 201 children, 1 or more full-time nurses shall be employed Affiliated preschools of elementary and junior high schools that already employ full-time nurses may be exempt from employing additional nurses" (Laws \& Regulation Database, 2017). By the end of 2016 academic year, there were 6310 private and public preschools in Taiwan (Ministry of Education, 2017). To employ nurses at preschools, its major concern is that preschool children are low in protective capabilities, and group life may have the higher risks of group infections. They need special attention in both psychological care and health care. Therefore, there are requirements of employing nurses in Taiwan's preschools
(Tainan City Government, 2017). Generally speaking, staff nurses shoulder the responsibility of taking care of patients. With the progress of time and the expansion of the scope of nursing, staff nurses are required to promote their professional and core competence to maintain their professional competitiveness (Ironside, 2008). Therefore, due to the different sites of practice, the degree of job satisfaction and innovation differ among staff nurses.

Professional autonomy is an important foundation and one of the guidelines for the professionalism for professionals. When the operation specification, procedure, and policy affect their works, they can offer criticism and propose effective suggestion according to the problem actively. Moreover, they enjoy certain degree of authorization in their works $(\mathrm{Lu} \&$ Cheng, 2007). Professional autonomy of nurses is the capabilities for nurses to complete their works independently, and the abilities to find out ways to accomplish their duties with the competence in self-determination and 
independent judgment. Insisting on departing from the perspectives of law, ethics, and moral, they hold fast to their nursing professionalism (Mrayyan, 2005). It is essential to regard the construction of a positive work environment as an important task. It is hoped that by providing a safe, autonomous, professional and effective communication environment to promote the work efficiency, the will to practice, retention rate, and job satisfaction of staff nurses to maintain an appropriate nursing manpower in order to provide patients with safe and continuous care (International Council of Nurses, 2007; Registered Nurses Association of Ontario, 2006). Suitable awards and reasonable increases in wages, and pay adjustment can motivate the morale of nurses (Kao, 2011; Liu, Fang, Yin, Liou, 2016).

Liu, Aungsuroch and Yunibhand (2016) suggest that the job satisfaction of nurses are threefold: (1) Work environment satisfies staff nurses' expectations; (2) work conditions bring staff nurses happiness; and (3) staff nurses feel the values and fairness in their works. Generally speaking, nurses have high satisfaction on internal conditions, such as the quality of self-care, interrelationship, and social support; however, they have low satisfaction on external conditions, such as human resources, wages, welfare, and promotion (Yen, $\mathrm{Ku}, \mathrm{Wu}, \mathrm{Au} \&$ Wang, 2011; Lee, Wu \& Feng, 2013). The job satisfaction of nursing is highly related to "terms and organization environment of work," "work pressure," "role conflicts and role ambiguity," "role awareness and role contents," and "organization commitment and professional commitment" (Lu, Barriball, Zhang \& While, 2012). Likewise, the job satisfaction of nursing is a synthesized concept of professional autonomy, work environment, wage and welfare, and leadership development.

Moreover, McSherry and Douglas (2011) point out that nurses' innovation create and constitute new ways of working for nurses. With new technology, system, theory and related cooperation partners, it is possible for them to provide enhanced and improved services to patients. Hughes (2006) and Holleman, Poot, Mintjes-de Groot, van Achterberg (2009) suggests that innovation in nursing means to using new thinking, skills, and processes in medical services to minimize medical cost, satisfy patients' different needs, and see improvements in nursing work to accomplish the ends of promptness and efficiency. Amo
(2006) argues that innovation in nursing implies staff participation in the improvements of nursing work, the invitation of others to participate in nursing work, and the capability of using improvement scheme in nursing themselves. Knol and van Linge (2009) propose that innovation of nursing personnel includes the degree of acceptance in the results of innovation and the seeking of others' support and cooperation in innovative activities. This innovative process comes in five stages: obtaining information on innovation, formulation of positive attitude towards innovation, choice of innovation items, consolidation of innovation items, and the blending of innovation item into everyday life (van der Weide \& Smits, 2004). Therefore, innovation in nursing is an integrated concept that includes knowledge creation, innovative behavior, innovative capability, and innovation diffusion (Weng, Huang, Chen, Chang, 2013; Weng, Huang, Lin, 2013; Weng, Huang, Huang, Wang, 2012; Huang, Weng, Lo, 2014). Likewise, this study aims to examine the job satisfaction of nursing work with the staff nurses in preschools in Taiwan as the object of study to explore the influence of job satisfaction of nursing work on the innovation of nursing. It is hoped that the research results can offer references to the recruitment of nursing man power and policy making in Taiwan.

\section{METHODOLOGY}

\subsection{Research Design and Participants}

This project was approved by the Institutional Review Board (ref.: IRB 1031106). According to the Directory of School at All Levels 2014 published by the Department of Statistics, Ministry of Education, there were about 650 preschools (Ministry of Education, 2014). This study employed a complete survey (full-scale survey), with nursing personnel as tests. The total of 650 questionnaires were sent, and received 219 valid ones $(33.69 \%)$. The testing time was one month, from January 6, 2015 to February 6, 2015. All the questionnaires were sent with anonymous return envelope.

\subsection{Research Tools}

This study used questionnaire as the research tool, including three sections; personal attributes, job satisfaction scale, and innovative work scale. The design of the questionnaire was conducted and developed in accordance with references to the researchers' experiences and research foundation in nursing administration, and related studies of local and international experts. 
All questionnaires were verified with expert validity. Three senior and experienced nursing personnel were consulted for the comments on the appropriateness regarding the necessity of the contents, distribution, and wording for suggestions for revisions.

(1)Questionnaire on personal attributes: This includes three questions; gender, age, and education. (2) Job stress questionnaire: designed with revision according to $\mathrm{Lu}$ et al., (2012), including professional autonomy, work environment, wage and welfare, and leadership development, with 4 sections and 26 questions. Regarding perceptions, 5 indicates the feeling of very strong stress, and 1 indicates no stress at all. Regarding job satisfaction, 5 indicates highly satisfied, and 1 indicates highly dissatisfied. The 5-point Likert scale was used to measure the data. In this research, Cronbach's $\alpha$ coefficient was 0.96. (3) The innovative scale was designed with reference to Weng, Huang, Chen, Chang (2013); Weng, Huang, Lin (2013); Weng, Huang, Huang, Wang (2012); Huang, Weng, Lo (2014), with revisions. It included knowledge creation, innovative behavior, innovative capability, and innovative diffusion, with 4 sections and 30 questions. The 5-point Likert scale was used to measure the degree of nursing personnel's acceptance of innovation. Regarding the degree of acceptance, 5 indicates the feeling of very strong stress, and 1 indicates no stress at all. Regarding the frequency of perception, 5 indicates always feel stress, and 1 indicates never feel stress at all. In this section, Table1. Descriptive Statistics $(n=219)$
Cronbach's $\alpha$ coefficient was 0.93 . Regarding the overall validity analysis of the empirical data, Cronbach's $\alpha$ coefficient was 0.928 . Therefore, the empirical data of this research communicates certain degree of validity.

\subsection{Statistical Analysis}

Data analysis in this research: This research used Excel to compile the data and construct the files, and SPSS22.0 was used to construct the statistics data. Descriptive statistical analysis was used to describe personal attributes, and the scales' scores. Pearson analysis was used to test the basic information of the continuous data, and to analyze the association between different scales. Regression analysis is a predictive method employing the relational analysis of two or more independent variables and one dependent variable to construct a forecasting model.

\section{RESULTS}

\subsection{Distribution of Personal Attributes}

In this survey, the results indicate that there were 219 valid questionnaire respondents, as shown in Table 1. Regarding the gender of the respondents, they were all female. Regarding the aspect of "age", most were 41-50 years old. About 90 (41.1\%) were 31-40; 89 were 31-40 (40.6\%); and only 16 were $21-30$ (7.3\%). Regarding the "education", most were senior high school graduates, with 117 (36.7\%); then, it was the junior college, 95 (43.4\%) (Table1).

\begin{tabular}{|l|c|c|}
\hline \multicolumn{1}{|c|}{ Characteristics } & $\mathrm{n}$ & $\%$ \\
\hline Age (years) & & 7.3 \\
\hline $21-30$ & 16 & 40.6 \\
\hline $31-40$ & 89 & 41.1 \\
\hline $41-50$ & 90 & 11.0 \\
\hline$>51$ & 24 & \\
\hline Education level & & 43.4 \\
\hline Junior college & 95 & 53.4 \\
\hline Senior high school & 117 & 3.2 \\
\hline University & 7 & \\
\hline
\end{tabular}

\subsection{Pearson Correlation Analysis}

In order to find out the relation between the variables, the Pearson correlation matrix was used to verify the degrees of satisfaction and the correlation of the eight dimensions in innovation and the overall association among the perspectives in innovation. The results indicate that (Table 2), the correlation between professional autonomy and work environment is the highest $(\mathrm{r}=0.723, \mathrm{p}<0.05)$. The correlation between work environment and leadership development is the highest $(\mathrm{r}=0.695, \mathrm{p}<0.05)$. Wage and leadership development were highly related $(r=602 p<0.05)$. The correlation between leadership development and innovative diffusion is the highest $(\mathrm{r}=0.255, \mathrm{p}<0.05)$. Innovative behavior and innovative capability, innovative diffusion and knowledge creation are highly related $(r>0.822, \mathrm{p}<0.05)$. 
The Influence of Nursing Job Satisfaction on Nursing Innovation: An Examination of the Conditions of Nurses in Public Preschools in Taiwan

Table2. Pearson Correlation Analysis

\begin{tabular}{|l|l|l|l|l|l|l|l|l|}
\hline \multicolumn{1}{|c|}{ Measure } & \multicolumn{1}{|c|}{$\mathbf{1}$} & $\mathbf{2}$ & $\mathbf{3}$ & $\mathbf{4}$ & $\mathbf{5}$ & $\mathbf{6}$ & $\mathbf{7}$ & $\mathbf{8}$ \\
\hline 1. Professional Autonomy & $\mathbf{1}$ & & & & & & & \\
\hline 2. Work Environment & $.723^{* *}$ & $\mathbf{1}$ & & & & & & \\
\hline 3. Wage and Welfare & $.460^{* *}$ & $.375^{* *}$ & $\mathbf{1}$ & & & & & \\
\hline 4. Leadership Development & $.773^{* *}$ & $.695^{* *}$ & $.602^{* *}$ & $\mathbf{1}$ & & & & \\
\hline 5.Innovative Behavior & $.183^{* *}$ & $.185^{* *}$ & $.340^{* *}$ & $.250^{* *}$ & $\mathbf{1}$ & & & \\
\hline 6.Iinnovative Capability & .118 & .113 & $.289^{* *}$ & $.215^{* *}$ & $.822^{* *}$ & $\mathbf{1}$ & & \\
\hline 7. Innovation Diffusion & $.156^{*}$ & $.169^{*}$ & $.380^{* *}$ & $.255^{* *}$ & $.899^{* *}$ & $.893^{* *}$ & $\mathbf{1}$ & \\
\hline 8. Knowledge Creation & .073 & $.133^{*}$ & $.291^{* *}$ & $.212^{* *}$ & $.852^{* *}$ & $.912^{* *}$ & $.919^{* *}$ & $\mathbf{1}$ \\
\hline
\end{tabular}

\subsection{Analysis of Job Satisfaction of Nursing Work and Nursing Innovation}

This research continued to compare and analyze the influence of job satisfaction on innovation regarding the nursing personnel. When conducting the regression analysis, the controlled variable and the independent variable may constitute the problem of collinearity. In this research, variation inflation factor $(\mathrm{VIF}<10)$ and condition index $(\mathrm{CI}<10)$ of related variables were tested to avoid the problem of collinearity. Regarding the testing results of the regression analysis and difference testing of innovative behavior, the $\mathrm{F}$ statistic was 3.900 ( $p$ $<0.001)$. Regarding the regression analysis and difference testing innovative capacity, the $\mathrm{F}$ Table3. Multiple Regression Analysis

\begin{tabular}{|c|c|c|c|c|c|c|c|c|}
\hline \multirow[t]{2}{*}{ Measure } & \multicolumn{2}{|c|}{$\begin{array}{l}\text { Innovative } \\
\text { Behavior }\end{array}$} & \multicolumn{2}{|c|}{$\begin{array}{l}\text { Iinnovative } \\
\text { Capability }\end{array}$} & \multicolumn{2}{|c|}{$\begin{array}{l}\text { Innovation } \\
\text { Diffusion }\end{array}$} & \multicolumn{2}{|c|}{$\begin{array}{l}\text { Knowledge } \\
\text { Creation }\end{array}$} \\
\hline & Beta & $t$ & Beta & $t$ & Beta & $t$ & Beta & $t$ \\
\hline \multicolumn{9}{|l|}{ Age(years) (RG: 41-50) } \\
\hline $21-30$ & .046 & .660 & .069 & .970 & .100 & 1.467 & .077 & 1.093 \\
\hline $31-40$ & -.004 & -.061 & .074 & .993 & .088 & 1.237 & .018 & .246 \\
\hline$>51$ & .032 & .468 & .083 & 1.178 & .130 & 1.942 & .085 & 1.229 \\
\hline $\begin{array}{l}\text { Education level (RG: Senior high } \\
\text { school ) }\end{array}$ & & & & & & & & .077 \\
\hline Junior high school and under & .099 & 1.486 & .058 & .836 & .081 & 1.234 & .005 & -.742 \\
\hline College and above & .004 & .061 & -.030 & -.411 & -.009 & -.136 & -.053 & -1.465 \\
\hline 1. Professional Autonomy & -.059 & -.529 & -.102 & -.892 & -.110 & -1.007 & .249 & $2.213^{*}$ \\
\hline 2. Work Environment & .036 & .36 & -.023 & -.226 & .028 & .289 & .058 & .580 \\
\hline 3. Wage and Welfare & .249 & $3.051 * *$ & .239 & $2.838 * *$ & .327 & $4.065 * * *$ & .236 & 2.848* \\
\hline 4. Leadership Development & .117 & .974 & .161 & 1.305 & .118 & 1.000 & .218 & 1.793 \\
\hline \multicolumn{9}{|l|}{ Model explanation force change } \\
\hline$R^{2}$ & \multicolumn{2}{|l|}{.158} & \multicolumn{2}{|l|}{.106} & \multicolumn{2}{|l|}{.186} & \multicolumn{2}{|l|}{.133} \\
\hline Adj. $R^{2}$ & \multicolumn{2}{|l|}{.117} & \multicolumn{2}{|l|}{.063} & \multicolumn{2}{|l|}{.147} & \multicolumn{2}{|l|}{.091} \\
\hline $\mathrm{F}$ & \multicolumn{2}{|c|}{3.900} & \multicolumn{2}{|l|}{2.475} & \multicolumn{2}{|c|}{4.747} & \multicolumn{2}{|c|}{3.179} \\
\hline $\mathrm{P}$ & \multicolumn{2}{|c|}{$.000 * * *$} & \multicolumn{2}{|c|}{$.008 * *$} & \multicolumn{2}{|c|}{$.000 * * *$} & \multicolumn{2}{|c|}{$.001 * * *$} \\
\hline
\end{tabular}

Note: $* * * \mathrm{p}<.001, * * \mathrm{p}<.01, * \mathrm{p}<.05$

\section{DISCUSSION}

Nurses occupy about half of the medical work in human resources. No matter whether their work environment is in the hospital, community, or school, the professional nursing capacity of statistic was $2.475\left({ }^{p}<0.05\right)$. The $\mathrm{F}$ statistic of the regression analysis and difference testing of innovation diffusion was 4.747 ( $p<0.001)$. The $\mathrm{F}$ statistic of the regression analysis and difference testing of the creation of knowledge was $3.179(p<0.05)$. From the regression model shown in Table 3 , it is known that regarding the three factors of the influence of innovative behavior, innovative capacity, and innovative diffusion, the statistic of wage and welfare show to be significant $(p<0.05)$, influencing the factors of knowledge creation, professional autonomy, and wage and welfare $(p<0.01)$. 
With the advancement of medical technology and the decrease in birth rate, the demographic structure of Taiwan is changing. With the increase of older population, and the decrease of newborn babies, it leads to the changing in family structure. The government's family policies tend to focus on the origin of the issue of the "population," with the hope to create a friendly environment to health promotion. Its package policies tend to point to the care and education measures of young children (Duan \& Ma, 2013). The average manpower in Taiwan's preschools is 1 . This research discovered that due to the difference in the site of practice, nurses tend to have negative satisfaction on the work environment in preschools. Perhaps it is because there is no backup nursing manpower that constitute the result of negative satisfaction.

Then, from collecting the data, it was discovered that, due to the limitations of laws and regulations in Taiwan, the employment status of nurses in preschools may have different wages and welfare when compared with those working in medical institutions doing similar work. Because of their work environment, it results in low innovative capacities. It also affects the job satisfaction and innovative capacity of nurses. Rogers (1995) suggests that the innovation of new things needs to be conducted through particular channels. With the evolution in time, it will be accepted by people to result in diffusion.

Finally, preschool nurses are school nurses. In Taiwan, school nurses cover the domains of both "education" and "healthcare." As there is no clear positioning of the role and function of school nurse in Taiwan, it causes the difficulty in defining whether school nurses are nursing by duty or nursing by profession? Or they are administrative personnel? Nurses work at schools are because of their background in nursing that satisfy the demand of professional in campus to promote the hygiene and healthcare and shoulder the responsibilities of taking care of children's healthcare in campuses. Regarding the object of service, school nursing service should be regarded as nursing professionals in the scope of service. This research discovered that there are great differences regarding the work contents of nurses in preschools. Therefore, the Taiwan government should regulate and establish the domain of services of nursing in preschools.

\section{CONCLUSION}

With the progress in the obtaining of information and teaching strategies, with cloud learning through the internet, especially nurses in preschools, can learn without the stress of space and time to enhance their nursing competence and innovative capacity at the same pace with the nursing personnel working in medical institutions.

\section{ACKNOWLEDGMENTS}

The authors would like to thank the Tainan Municipal Hospital, Taiwan for financially supporting this research under Contract No. 104-01.

\section{REFERENCES}

[1] Amo, B. W. (2006). Employee innovation behaviour in health care: the influence from management and colleagues. International nursing review 53 (3), 231-237.

[2] Duan, H. Y., \& Ma, T. L. (2013). The development strategies for private preschools to adapt to the transition society of Taiwan. Journal of Early Childhood Education \& Care, 10, 1-17.

[3] Holleman, G., Poot, E., Mintjes-de Groot, J., \& van Achterberg, T. (2009). The relevance of team characteristics and team directed strategies in the implementation of nursing innovations: a literature review. International Journal of Nursing Studies, 46(9), 1256-1264.

[4] Huang, C, Y., Weng, R. H., \& Lo, Y. S. (2014). Exploring the work performance of innovative nurses in hospitals: the views of nurses, nurse managers and customers. Taiwan Journal of Public Health, 33(5), 497-512.

[5] Hughes, F. (2006). Nurses at the forefront of innovation. International Nursing Review, 53(2), 94-101.

[6] International Council of Nurse. (2007). Positive practice environments: Quality workplaces $=$ quality patient care. Retrieved from http://www.icn.ch/indkit2007.pdf

[7] Ironside, P. M. (2008). Safeguarding patients through continuing competency. Journal of Continuing Education in Nursing, 39(2), 92-94.

[8] Kao, C. C. (2011). Multi-aspects of Nursing Manpower in Taiwan. Cheng Ching Medical Journal, 7(3), 41-46.

[9] Knol, J., \& van Linge, R. (2009). Innovative behaviour: the effect of structural and psychological empowerment on nurses. Journal of Advanced Nursing, 65(2), 359-370.

[10] Laws and Regulation Database (2017). Early childhood education and care Act. Retrieved form http://law.moj.gov.tw/ LawClass/ LawAll. aspx?PCode $=\mathrm{H} 0070031$ 
[11] Lee, C. L., Wu, L. C., \& Feng, M. C. (2013). Nurses' Job Satisfaction in a Medical University Hospital in Southern. The Kaohsiung Journal of Nursing, 30(3), 23-35.

[12] Liu, Y. C., Fang, C. C., Yin, T., \& Liou, Y. F. (2016). A Project on the Reduction of Newly-Employed Nurse Turnover Rate in a Teaching Hospital on an Island. Yuan-Yuan Nursing, 10(1), 45-53.

[13] Liu, Y., Aungsuroch, Y., \& Yunibhand, J. (2016). Job satisfaction in nursing: A concept analysis study. International Nursing Review, 63(1), 84-91.

[14] Lu, H., Barriball, K. L., Zhang, X., \& While, A. E. (2012). Job satisfaction among hospital nurses revisited: A systematic review. International Journal of Nursing Studies, 49(8), 1017-1038.

[15] Lu, I. Y., \& Cheng, Y. H. (2007). The study on the relationships among the factors of internal service quality, service ability, job satisfaction and external service quality-The case of nurse. Journal of Quality, 14(2), 161-179.

[16] McSherry, R., \& Douglas, M. (2011). Innovation in nursing practice: a means to tackling the global challenges facing nurses, midwives and nurse leaders and managers in the future. Journal of nursing management, 19(2), 165-169.

[17] Ministry of Education (2017). Kindergarten (Childish) Fact Sheet (80 105 school year). Retrieved form https://depart.moe. edu.tw/ed 45 00/cp.aspx?n=1B58E0B736635285\&s=D04C7 4553DB60CAD

[18] Mrayyan, M. T. (2005). American nurses' work autonomy on patient care and unit operations. British Journal of Nursing, 14(18), 962-967.

[19] Registered Nurses Association of Ontario. (2006).Healthy Work Environment Best Practice Guidelines: Collaborative Practice Among Nursing Teams. Retrieved from http:// www.rnao.org/Storage/23/1776_BPG_ Collaborative_Practice.pdf
[20] Rogers, E. M. (1995). Diffusions of innovations (4th ed.). New York, NY: Free Press.

[21] Tainan City Government (2017). Child Care Act and the implementation details of the specific methods referred to the nursing staff explained. Retrieved form http://www.ece. moe. edu.tw/wp-content/ uploads/ 2013/10/ 3515- 10 20068564102.08.06\%Е5\%B9\%BC\%Е7\%85\% A7\%Е6\%B3\%95\%Е5\%8F\%8A\%Е5\%85\%B $6 \% \mathrm{E} 6 \% 96 \% \mathrm{BD} \% \mathrm{E} 8 \% \mathrm{~A} 1 \% 8 \mathrm{C} \% \mathrm{E} 7 \% \mathrm{~B} 4 \% \mathrm{~B} 0$ $\%$ Е5\%89\%87\%Е6\%89\%80\%Е6\%8C\%87\%Е 7\%89\%В9\%Е7\%В 4\%84\%Е6\%96\%В 9\%Е5\% $\mathrm{BC} \% 8 \mathrm{~F} \% \mathrm{E} 7 \%$ BD\% $\mathrm{AE} \% \mathrm{E} 8 \%$ AD\% $\mathrm{B} 7 \%$ $\mathrm{E} 7 \% 90 \% 86 \%$ E4\% BA\% BA\%E5\% 93\% A1\% Е9\%87\%8B\%Е7\%96\%91\%Е6\%8E\%9B\%Е7 $\%$ B6\%B2\%E6\%A0\%BC\%E5\%BC\%8F.pdf

[22] Van der Weide, M., \& Smits, J. (2004). Adoption of innovations by specialised nurses: personal, work and organizational characteristics. Health Policy, 68(1), 81-92.

[23] Weng, R. H., Huang, C. Y., \& Lin, T. E. (2013). Exploring the cross-level impact of market orientation on nursing innovation in hospitals. Health care management review, 38(2), 125-136.

[24] Weng, R. H., Huang, C. Y., Chen, L. M., \& Chang, L. Y. (2013). Exploring the impact of transformational leadership on nurse innovation behavior: a cross-sectional questionnaire survey. Journal of nursing management, 23(4), 427-439.

[25] Weng, R. H., Huang, C. Y., Huang, J. A., \& Wang, M. H. (2012). The cross-level impact of patient safety climate on nursing innovation: a cross-sectional questionnaire survey. Journal of clinical nursing, 21(15-16), 2262-2274.

[26] Yen, F. H., Ku, Y. C., Wu, L. C., Au, W. Y., \& Wang, C. (2011). A study of the satisfaction of nursing practice environment in a medical center in southern Taiwan. The Kaohsiung Journal of Nursing, 28(1), 11-22 。

Citation: Yu-Hua Yan, Chih-Ming Kung, Yu-Li Lan, Liang-Hsi Kung, Chao-Jung Lee. The Influence of Nursing Job Satisfaction on Nursing Innovation: An Examination of the Conditions of Nurses in Public Preschools in Taiwan, ARC Journal of Nursing and Healthcare. 2017; 3(4): 9-14. doi: dx.doi.org/ 10.20431/2455-4324.0304003.

Copyright: (C) 2017 Authors. This is an open-access article distributed under the terms of the Creative Commons Attribution License, which permits unrestricted use, distribution, and reproduction in any medium, provided the original author and source are credited. 